\title{
Building a culture of trust in Vietnam today: a philosophical perspective
}

\author{
Nghia Thu Nguyen
}

DOI: 10.18355/XL.2021.14.03.14

\begin{abstract}
Trust is the most fundamental spiritual value of social life, motivating people toward good values. In Vietnam today, there is an alarming reality of trust being eroded due to the falsehood and corruption of some governmental officials. Trust is also weakened and distorted in everyday life. Hence the question: how to re-establish trust? This is a compulsory obligation of the Communist Party, State, Government, and the responsibility of each person. This article (1) presents the concepts and understandings of trust, drawing comparisons between selected Vietnamese and foreign scholars; (2) analyzes the role of trust in social life; (3) identifies the crisis of trust that currently exists in Vietnam; (4) as well as points out the causes that lead to this problem. It also explores the transition from trust to distrust as and the desire to come up with possible solutions to restore trust in society, especially in the public sector in Vietnam today.
\end{abstract}

Key words: Concept of trust, culture of trust, Vietnamese society, corruption, social responsibility

\section{Introductory Remarks on the Concept of Trust}

The issue of trust carries an utmost importance in the lives of individuals and societies. It defines interpersonal as well as social relationships and lays ground for cohesive human communities. Despite being with us throughout the history of humankind, questions related to 'What is trust?' and 'How should trust be cultivated and manifested' in our daily lives remain relevant and, to some degree, contentious.

Philosophical understanding of this issue necessarily overlaps with analyses of human emotions and attachments, which calls for a more holistic approach to the subject. Before the rational, thinking human subject intentionally deliberates on the question of trust, he/she experiences this phenomenon personally, intuitively, as part of one's own life-narrative (Haidt, 2006). Thus, trust as a psychological state accompanies humans from the moment of their birth, enabling them to recognize and evaluate the world and one's attitude to it. Furthermore, trust is not an isolated phenomenological experience, as it entails hope. To trust means that one is not skeptical, anxious, disappointed, or indifferent to oneself or the outside environment. On the contrary, trust implies a positive outlook on one's immediate interactions with the surround environment, including other human agents. There are some other concepts related to trust, such as "belief," "faith," "confidence" - all of which help us understand the complexity of this phenomenon (Vanzant, 2015).

In any case, concepts of trust, though linguistically contingent, are derived from the personal experiences of human agents as thinking and feeling moral subjects. Trust is formed by the environment, education, culture, and life experiences of each individual. Genuine trust is an indispensable element of one's subjective perception of happiness. In addition, trust is a value. However, it is not easy to form this value because of the need to integrate and harmonize many qualities and abilities in one's character and life. Trust is therefore built and formed against the background of various influences.

In sociological research, the place and role of trust in social systems are analyzed (Covey - Merrill, 2006; Giddens, 1996; Marty, 2010). Trust is one of many social structures, an element of social reality. It exists in our view of the world around us.

XLinguae, Volume 14 Issue 3, June 2021, ISSN 1337-8384, eISSN 2453-711X 
Pictures of the world can be real or imagined, but these images assembled and organized in the memory of a thinking subject allow for trust emerge and develop.

In society, there is a great need for trust. Without it, social relations become unstable and ultimately unsustainable. A deficit of trust on the social level results in random possibilities of social development with anarchy and lawlessness being the gravest socio-political outcomes. In recent years, research on trust has been particularly relevant for our general understanding of who the human person is, what motivates him/her, and what constitutes a happy and sustainable life on the individual and community levels (Yeo - Green, 2015; Covey - Merrill, 2006; Christensen - Eriksen, 2021 ; etc.). Such research has become especially important for the Vietnamese social environment because of the ongoing changes taking place in Vietnamese society. Some of these changes are for the better; others are for the worse with bad consequences. "The liberalization of Vietnam's economy has brought abrupt shifts in management and institutional oversight. Major social changes followed suit resulting in considerable detrimental effects in terms of new or resurfacing social phenomena." (Do - Valco, 2018: 608) As Do and Valco further remind us, "Rampant cases of corruption, human trafficking, abductions of women, the kidnappings of children, a strong surge in domestic violence and sexual abuses, growing cases of child labor exploitations are all too common occurrences in a society that had not long ago prided itself with order and social justice." (Do - Valco, 2018: 608) These phenomena cause new anxieties and an overall loss of the sense of security, resulting in a considerable decline of trust.

\section{Complementary Definitions of Trust}

There are many concurrent, complementary concepts of trust as we can see on the examples provided in the section below. In the book Living in an Age of Mistrust: An Interdisciplinary Study of Declining Trust and How to Get It Back, social scientists Karen Cook, Russell Hardin, and Margaret Levi argue that trust exists "when one party to the relation believes the other party has the incentive to act in his or her interest or to take his or her interests to heart." (Yeo - Green, 2015: 4-5) Frost, Stimpson, and Maughan are three social psychologists. They define trust as "an expectancy held by an individual that the behavior of another individual or group of individuals would be altruistic and personally beneficial to himself" (Yeo - Green, 2015: 5). Iyanla Vanzant, in the book Trust mastering the four essential trusts, claims that "Trust is the way of thinking, being, and living that grows from experience, desire, and choice. It is a demonstration of hope, courage, and perseverance that moves the mind, heart, and body beyond what is known into the realm of what is possible" (Vanzant, 2015: xvii-xviii). Anthony Giddens argues in his Social Theory and Modern Sociology that "Trust, it might be said, is a device for stabilizing interaction. To be able to trust another person is to be able to rely upon that person to produce a range of anticipated responses" (Giddens, 1996: 136). In his book The SPEED of Trust: The One Thing that Changes Everything, Stephen M.R. Covey revealingly points out that:

"trust impacts us 24/7, 365 days a year. It undergirds and affects the quality of every relationship, every communication, every work, every business venture, every effort in which we are engaged. It changes the quality of every present moment and alters the trajectory and outcome of every future moment of our lives-both personally and professionally. Contrary to what most people believe, trust is not some soft, illusive quality that you either have or you don't; rather, trust is a pragmatic, tangible, actionable asset that you can create much faster than you probably think possible" (Stephen - Covey, 2006: 1-2).

These definitions are complementary rather than mutually exclusive. They help us see that trust is a complex phenomenon involving several parties (human agents and/or 
institutions), which are basic to human social living and interactions. Basic trust is relational in character. "Trust is not a social substance, a medium, or a mysterious entity but rather a set of social practices, defined by our choices, to trust or not to trust." (Flores - Solomon, 1998: 205) Considering the importance of recognizing and accepting one's vulnerability, human interdependence, and a fundamental relational character of human lives invites serious critique of the overall individualizing trends that we see in the West and (increasingly now) also in South-East Asian societies. As such, trust needs to be highly valued and intentionally cultivated for any society or human relationships to thrive (Schweidler, 2020).

We believe that trust is a valuable spirit formed in each person's thoughts, associated with aspirations and dreams about the future. It is the driving force that motivates each person to overcome all challenges and difficulties of life.

\subsection{Foundations of Trust}

Uslaner (2002) sees trust rooted within a moral foundation, based on an ethical assumption that "others share your fundamental moral values and therefore should be treated as you would wish to be treated by them" (Yeo - Green, 2015: 5). Francis Fukuyama (1996) adds that "Trust arises when a community shares a set of moral values in such a way as to create regular expectations of regular and honest behavior" (Yeo - Green, 2015: 5). Martin Hollis (1998) combines elements of reciprocity with the pursuit of the common good as the basis for his definition of trust. In the book "Trust mastering the four essential trusts," Iyanla Vanzant (2015) reminds us that "Trust is a process that develops with and depends on experience and practice" (Vanzant, 2015: xvii). For Stephen and Covey, "trust means confidence" (Stephen Covey, 2006: 5). As they further elaborate:

"The opposite of trust - distrust - is suspicion. When you trust people, you have confidence in them - in their integrity and in their abilities. When you distrust people, you are suspicious of them - of their integrity, their agenda, their capabilities, or their track record. It's that simple. We have all had experiences that validate the difference between relationships that are built on trust and those that are not. These experiences clearly tell us the difference is not small; it is dramatic" (Stephen - Covey, 2006: 5).

\subsection{Typology of Trust}

Existing typologies of trust typically reflect the four overlapping dimensions of reality as perceived by human subjects - the dimension of one's inner self (introspective dimension); the dimension of interpersonal relationships; the dimension of the outside, non-personal environment; and the dimension of transcendence (construed in diverse ways, depending on one's spiritual/religious inclinations). When searching for a researcher who aptly defines the main types of trust reflecting all dimensions of the human experience, Iyanla Vanzant stood out above others as an inspiring model. Vanzant demonstrates why the four basic types of trusts - (1) Trust in Self, (2) Trust in God, (3) Trust in Others, and (4) Trust in Life - are all equally essential for us. She compares them to Oxygen, without which none of us can survive.

Regarding TRUST IN SELF Vanzant argues that all relationships of trust build on the foundation of a basic self-acceptance: "Trust yourself because you are worthy of your own time, energy, attention, and love. Trust yourself because you are here to learn, be healed, and develop a greater appreciation for the process of life unfolding through you. Trust yourself because it is the way you demonstrate that you are willing to embrace, engage, and enjoy life." (Vanzant, 2015: 268-269). When it comes to TRUST IN GOD, Vanzant points out that people whose lives are intentionally open to transcendence find their being anchored in something higher, which helps them live purposeful lives: "Trust in God because it is your sole purpose for being on the planet.

XLinguae, Volume 14 Issue 3, June 2021, ISSN 1337-8384, eISSN 2453-711X 
Trust in God because without that level of connection to the Source that gave you life, you will find yourself lost, alone, and searching for what you already have." (Vanzant, 2015: 270). Embracing one's relatedness and dependence on the ultimate Other (either in the form of a personal God or impersonal force/principle) leads to a qualitatively higher openness to trust relationships with other human beings. Vanzant recognizes that this process can at times be painful and challenging. Yet, as she points out, it constitutes an important step in one's maturing and personal development. Speaking of the need to TRUST IN OTHERS, Vanzant points out the following: "Trust in others because it is the only way to fine-tune your instincts, deepen your ability to trust yourself and learn the depth of your capacity to love and forgive... Trust in others because you need people to facilitate and support your mental, emotional, and spiritual." (Vanzant, 2015: 272). Finally, Vanzant encourages humans to TRUST IN LIFE: "Trust the process of life because it is an incredible journey of wonder, adventure and evolution that you can experience only in direct proportion to your willingness to trust it." (Vanzant, 2015: 273). Life understood holistically as the sum of all being and experience, perceived cognitively, emotionally, and intuitively at the same time by the human agent, is the dynamic context, the organic environment of one's personal development. It is the flow of evolution, the intricately woven web of relationships and attachments that defines who we are as persons based on our relatedness and responses to these realities.

In Vietnam, contemporary researchers identify and distinguish the role of trust in the following areas: (1) religion, (2) society, (3) science. In religion, trust is often equated or at least connected to one's faith in a belief system. According to Dang Nghiem Van, every religion includes a belief system (Dang, 1993: 304). Religious trust is the belief in the divine, the supernatural, which is unequally distributed to members of a religious community. Religious beliefs are supernatural, not based on reason and experiment. Religious beliefs need no conclusive proof. The object of such beliefs is the absolute. The absolute is typically perceived subjectively on the emotional and/or intuitive level. The content of religious beliefs depends on the religious doctrine and traditional religious practices, so there is a difference in religious beliefs among believers in different religions and in each religion. The difference in religious beliefs underscores the issue of religious diversity and the corresponding need for religious tolerance and religious dialogue (Nguyen, 2008). In measuring and evaluating religious beliefs, religious sociologists use indicators of religious behavior through participation in religious activities such as religious ceremonies, religious instruction, level of ritual understanding and religious doctrine, etc.

While we believe in the importance of a solid analysis of religious belief/trust, this dimension is not our main focus. In this article, we particularly want to emphasize social trust. Social trust is based on trust between individuals in society, formed and maintained on the basis of interactions between individuals. Intimate interactions can create a deep level of social trust.

\section{The Role of Trust in Social Life}

Trust is very important in social life. In every human relationship as well as in all social activities, in addition to ethical and human norms, trust constitutes the basic level of certainty and stability. Uslaner (2002) is correct to point out that "Trust is the chicken soup of social life. It brings us all sorts of good things, from a willingness to get involved in our communities to higher rates of economic growth and, ultimately, satisfaction to government performance" (Yeo - Green, 2015: 4). We need, therefore, to be reminded that "Issues of trust, and especially its absence, have been central to many other domestic and international issues." They determine the success or failure of negotiations and subsequent intra-national and international cooperation. In addition to this national and global dimension, equally important is the need to cultivate the moral imagination of among the populace, in which trust plays a key 
role. Absence of trust may "lead to moral decay at the individual and societal level" (Yeo - Green, 2015: 3-4) Studies show that there is "an asymmetry in the way we think about testimony about moral and descriptive matters" stemming from "different metaphysical beliefs about the relevant domains, or beliefs about the relative background levels of deception or disagreement." (Andow, 2020: 456)

Even in banking transactions, where the economic and legal principles must be strictly adhered to, trust is at the forefront. Vietnamese people often use the phrase "Trust is more precious than gold." This motivates people to consider the importance of trust and carry on their resolve to replenish it. If one loses the trust of one's friend, partner in life or in business, one loses everything because, as they say, "one-time failure, alltime distrust."1 Karl Marx (1818-1883) agrees with the importance of healthy social relationships based on mutual trust, claiming that "people are the sum of social relationships." ${ }^{2}$ Trust is respected and heeded in all social relationships: those between parents and children; between teachers and students, doctors and patients, between the upper and lower classes, between partners or friends, neighbors ... everywhere. If we find ourselves in a relationship with someone but this relationship is marked by a lack of trust, it may be difficult to work together or play together.

Trust is also very important in each individual's life. When we do something without an elementary trust (e.g., in ourselves or in the good intentions of the other), it will most likely result in a failure. If an individual loses his trust (belief) in the basic righteousness of the given socio-political system, he might as well become an evil, selfish person. It can be said that trust is the driving force and connecting social glue of our societies (Rolin, 2020). The collapse of trust on the social level results in dire consequences (Yang - Dong - Chen, 2021: 546-547).

\section{The crisis of Trust in Contemporary Vietnam}

Therefore, it is important to carefully analyze what is happening in Vietnamese society today regarding the perceived level of trust towards government institutions and a broader cultural and interpersonal level. Trust, in general, seems to be lack among the people, especially in cases when the underprivileged dealt with those in power. The degree of deterioration is now threatening the social stability in Vietnam. The lack of trust can be traced mainly to the rising corruption and a widening gap between the rich and the poor. Inequality in wealth and opportunities in our society has been a major concern ever since the beginning of the Doi Moi Reform started in 1986, although the late 1980s and 1990s were not as critical as the past two decades. The worrisome decay of social capital has taken place in the more recent past, resulting in the decline in solidarity and mutuality or even a loss of faith in the common purpose, the common good.

"The quality or strength of trust relations can be characterized as thin or thick," as Yeo and Green remind us (Yeo - Green, 2015: 33). The social structure and political culture in any country need to rely on the 'thick trust,' i.e., the more robust, fixed, and durable trust that provides a layout and necessary guidelines for human interactions. If a given society starts believing that "the only kind of trust that matters is one based on naked self-interest" (Yeo - Green, 2015: 40) - that is, a form of a 'thin,' instrumentalized trust, such society is in deep trouble. There are clear indications that Vietnam is struggling with the issue of a diminishing 'thick trust.' Consequences can

\footnotetext{
${ }^{1}$ This is a reference to a popular Vietnamese saying.

${ }^{2}$ More concretely, Marx says that "the essence of man is no abstraction inherent in a single person. In fact, it is the sum of all social relations." Cited in: (Dawei, 2015: 188; see also: Fromm, 1961).
}

XLinguae, Volume 14 Issue 3, June 2021, ISSN 1337-8384, eISSN 2453-711X 
be felt on the personal, national, as well as international levels. Vietnamese society is undergoing a series of transformations. On the surface, these transformations may seem mainly on the economic level with the corresponding transformations in social relations. However, the underlying transformation of emphases and expectations concerning trust is even more important (Dang et al., 2020).

Commenting on the nature of these fundamental societal transformations, Markova (et al., 2007) makes the case for two complementary issues:

"These transformations seem to comprise two related issues. On the one hand, we find that throughout these transformations, relatively more emphasis is being progressively placed on individuals and organizations. On the other hand, as far as interrelations are concerned, there is more emphasis on confidence and on trust as a reflected-upon and a calculated relation. That is to say, we talk about the trustworthiness of an individual as a property or a personal quality invoking others' trust in him or her, and about trust and trustworthiness as individual attributes of truster versus trustee. As a result of these transformations, trust/distrust has become a generalized social phenomenon in relation to anonymous and unidentified 'others"' (Markova et al., 2007: 20).

However, it is questionable whether trust as a commodified, calculated relation can fully substitute trust in the 'thick' sense. The changing social reality in Vietnam implies otherwise. The Communist Party of Vietnam is trying to cope with this challenge and offer solutions that would mitigate the detrimental consequences of a globalized market economy, including the rise of social inequality and consumerism, the increase in number of criminal offenses, and the spreading corruption - though some of these cannot be automatically ascribed to market economy alone. On the other hand, recent studies show that "good economic performance by the government was positively associated with a high level of trust in government." (Yang - Dong Chen, 2021: 545)

\subsection{The Communist Party and the State}

The fact that the people's trust in the State and Communist leadership has decreased is undeniable (Fforde - Homutova, 2017). As such, it is mentioned in some official documents of the Communist Party of Vietnam and official newspapers, for example:

"Together with it's achievements, the Party-building task continues to exhibit many shortcomings and weaknesses, some of which have been dealt with at several Party congresses, thus eroding the people's trust in the Party; if those shortcomings and weaknesses are not corrected, they will challenge the leadership of the Party and the survival of the regime. Some urgent problems are as follows: A not so small number of cadres and Party members, including those at the leadership and management level, including high-ranking cadres, have exhibited degeneration in political thinking, morality, and lifestyle reflecting the erosion of ideals, selfish individualism, opportunism, pragmatism, pursuit of money and power, corruption, wastage, irregularity, unprincipled behavior ..." (CPV, 2012: The Fourth Conference of the 11th Party Central Committee issued Resolution No.12-NQ/TW "Current urgent issues on Party building on 16 January 2012: https://tulieuvankien.dangcongsan.vn/van-kien-tu-lieuve-dang/hoi-nghi-bch-trung-uong/khoa-xi/nghi-quyet-so-12-nqtw-ngay16012012-hoi-nghi-lan-thu-4-ban-chap-hanh-trung-uong-dang-khoa-xive-mot-so-van-de-cap-553)

On the other hand, we see some positive changes. There have been recent cases of high-ranking officials being brought to the court and condemned for their corruption. The confidence of the public in governmental institutions has thus been boosted, and new hope emerged. Nevertheless, people continue to be apprehensive about senior 
officials of the Party and State government being pulled into corruption scandals and other major offenses. Such crimes are scary, and it continues to be sensitive to bring them to light and administer full justice. Instead of being suspicious of corruption, the Party leaders and government officials should have been those who inspire trust and belief that sustainable development of our society is possible and that Vietnam is on the path to a sustainable future. The case of the minister of Transport Dinh La Thang is a good example of how a corruption scandal creates tensions in the society (VNA, 2020). Many people want to know: Will this case be properly prosecuted, and will the truth be revealed? Are senior government officials reliable? Can we trust their words and outer appearance, the seeming decency that they pretend to adhere to each day?

\subsection{Education and Health Care}

We see similar challenges in the field of education. The phenomena that lead to distrust of the authority of teachers, such as teachers' abuse of students, including physical punishments, large scale frauds in testing and grading, tend to continue to grow in the Vietnamese education system. Alternatively, there have been cases of pupils' killing their teachers, parents forcing the pregnant teacher to kneel on the floor and thus be humiliated in front of the whole classroom, etc. These events take place in some areas of the country at many levels of education. Vietnamese officials have been struggling to identify the measures that are needed to rectify these abuses and make the school environment safer and more conducive to modern learning and personal growth. They understand that the area of education carries significant promises as well as responsibilities when it comes to shaping one's moral vision and personal character (Fisher - Tallant, 2020).

Similar issues, though perhaps even more serious, can be found in the field of healthcare. The social environment in state hospitals and clinics has detrimental effects on the professional ethics and personality development of many doctors and healthcare personnel. Underpaid and underappreciated, doctors and nurses are tempted to prescribe unnecessarily expensive drugs to their patients. It is no surprise that they (i.e., doctors and nurses) are motivated by a certain commission percentage from the pharmaceutical companies (Nguyen et al., 2018). Moreover, an increasing number of patients are encouraged to seek medical treatment in private clinics - at much higher costs, of course. In state-run medical facilities, lack of respect, neglect, and incompetence are rampant. Some doctors find it difficult to be reimbursed for their medical performance (services to patients) due to health insurance frauds and delays in due payments. Also, Vietnam has had to deal with a series of infant deaths due to allergic reactions to vaccinations. A lack of transparency plagues the organ transplantations procedures (such as in the case of kidney transplant in Can Tho), and big corruption scandals revolve around selling cancer treatment drugs, including selling fake medicine to cancer patients. Eight people died in Hoa Binh due to an unexplained malfunction of kidney machines in the local hospital, and more children died as a result of measles infection after local authorities had failed to issue the epidemic warning. Tragic deaths, incompetent treatment, and ever-increasing corruption cause people to distrust the healthcare providers and the whole system that guarantees the medical care of the Vietnamese citizens. We have witnessed instances of public outrage over these deficiencies, though this outrage was not expressed in the streets but rather on social networks (mainly Facebook). Unfortunately, these phenomena are not unique. Reasons behind these failures are various, ranging from implemented tools, existing mechanisms, and institutions to personal failures stemming from immoral characters. All of this affects people's trust.

XLinguae, Volume 14 Issue 3, June 2021, ISSN 1337-8384, eISSN 2453-711X 


\section{Attempts to Identify the Roots of the Crisis of Trust}

The crisis of trust has been mentioned in Vietnam. By the end of 2016, the Resolution of the $12^{\text {th }}$ Central Committee of the Communist Party of Vietnam (CPV, 2016: https://cpim.org/content/vietnam-12th-congress-report) has designated 27 degradation manifestations of political thought, morals, lifestyle, and political qualities. All these manifestations are considered direct causes behind the loss of trust in contemporary Vietnam.

Political and social scientists have identified public administration, bureaucracy, and the present legal system as important causes of the crisis of trust. Most of the public can readily identify with these scholarly results, even if the people's assessment is more intuitive than scientific. However, a more thorough analysis is in order here. Why should we blame the public administration or the legal system? Why is the state bureaucracy considered as one of the major causes behind the lack of trust on the side of the citizens? Interviews with people from various sectors and social classes will reveal that the fundamental problem is the prevalent disrespect towards what is just and righteous that is so typical among those in power. This trend then spreads over to people who come into contact with state officials both on national as well as local levels.

Regarding this cause, the Communist Party of Vietnam also acknowledges that faults can be found on the policy level. Some laws dealing with corruption, for example, are not strict enough, and even if they are, they are not implemented thoroughly and competently. Corrupted minds take advantage of imperfect legislation; villains will always use the incompetence of state officials to their advantage. As these corrupted individuals seem to be doing well (socially, economically, etc.), it only enforces the view among the general population that notions of righteousness and any corresponding attempts at its implementation are meaningless. Cases of unjust appointments of individuals into public offices have recently flooded Vietnamese public space, i.e., individuals who had close relations with high-ranking government officials. Thus, persons with little experience and low skills were given the power to decide the fate of countless people under their sphere of influence. Alternatively, there have been many urgent cases of officials who committed crimes yet were not held responsible by the courts. They feel (or act as if they felt) invulnerable, being shielded by senior officials of the government. However, the public demands justice. A bad example of people in power sheds a bad light on the whole society and weakens the personal determination of people to act justly and with compassion.

If a society suffers an acute lack of trust, every law will be twisted to suit the insatiable human hunger for power and profit. If government institutions cannot be trusted, people will be tempted to take justice into their own hands, which may result in more lawlessness and injustices. This is precisely what might happen when moral agents experience exhaustion and meaninglessness. In such situations, it becomes very difficult to motivate people to act justly, to give their best to their country and neighbors, to live with compassion, and accept their social responsibilities. Rebellions and insubordinations are more frequent when people lose trust and hope, and the whole society is plunged into a deep crisis.

Trust seems to be inversely proportional to falsehood and corruption. If trust is lacking, falsehood will increase, and this increase may be exponential. In a society where people are less and less trusting, all culture becomes permeated and affected with falsehood. In the end, everyone ends up tasting the bitter fruits of this crisis. This includes the realm of personal relationships, from marriage relationships to business relationships. Furthermore, it is important to remember that it is very difficult to regain trust after one has lost it. 


\section{Proposed Solutions to Regain Trust}

The Communist Party, along with the Vietnamese government, have tried to identify the roots of the present crisis of trust and attempted to rectify it. In recent times, there have been positive cases that bring hope that the situation has not gotten out of hand and can be changed for the better. One such example is the work of the General Secretary of the Communist Party of Vietnam, Mr. Nguyen Phu Trong. He has become known as a champion of fighting against corruption with the first positive results. State officials, including those in high positions (on the national level), wielding considerable power in matters under their jurisdiction, have been held accountable for their crimes and brought to trial. His fight, along with the accompanying efforts of his colleagues, has resulted in a changing trend in the people's perception of the government. Vietnamese citizens are learning to have trust in the Vietnamese leadership again.

In addition, many decisions of the Political Bureau about Party Members' corruption certainly help clean up the society. This should result in an increased level of trust in state institutions, governmental agencies, and cultural institutions. A more stable social environment will encourage better interpersonal relationships and stronger family structures.

Among the noteworthy efforts of the current government is the determination of Fomer Prime Minister Nguyen Xuan Phuc's government to build his administration on concrete reforms of institutions, mechanisms, and policies (VOV, 2021: https://vovworld.vn/en-US/news/pm-administrative-reforms-contribute-to-nationalachievements-963862.vov). Some of them have yet to be implemented and their influence assessed by scholars and politicians. However, the declared fight against corruption and the stated goal to establish new procedures and structures to promote justice and sustainable development are certainly commendable.

Vietnamese people's trust often surges to higher levels in difficult circumstances. When the Covid 19 pandemic happened, many countries around the world had hundreds of thousands of cases, hundreds of thousands of people died every day. The global economy was in decline. The danger of food insecurity, environmental pollution (etc.) had affected millions, but in Vietnam, life has always been maintained normally. The most valuable thing in the global crisis of Covid is to get back to normal life. To that end, Vietnam experienced a fierce and tense war run by a clear and decisive political system with solidarity and support from the entire people. Vietnam has gradually prevented the epidemic outbreaks, becoming a successful model for countries in the region and around the world in the war with Covid. It can be seen that, in the harsh circumstances of the pandemic, trust has created attitudes and acts of solidarity, energizing the will and resolve of the entire population to overcome difficulties. It helped leaders make informed decisions. Vietnam has been willing to sacrifice its immediate economic interests, put people's health first, and took action to protect their survival. At the same time, trust helps people live a meaningful life and have confidence in the nation's bright future once the pandemic crisis is overcome.

On August 6, 2020, the Ministry of Health launched a communication campaign to spread the message "Trust of victory" calling on the community to prevent and control the COVID-19 epidemic in a new normal state. The media campaign aims to call on all classes of people to fully implement disease prevention and control measures. At the same time, there has been a push to cultivate a suitable lifestyle, create healthy habits to live with the epidemic, establish a normal life in a new state, effectively fight the epidemic, and restore and develop the economy. In addition, the campaign stresses the importance of conveying the message of solidarity, calling to action, spreading charity to the community, especially the vulnerable group in society, and working together to fight against the epidemic.

XLinguae, Volume 14 Issue 3, June 2021, ISSN 1337-8384, eISSN 2453-711X 
It can be said that trust is a value. Under any conditions, trust always creates a harmonious connection between individuals and communities, helps individuals realize their roles and responsibilities in the community's relationship, and benefits the nation.

"Trust is a key moral and ethical component of transactional relationships. Without a clear understanding of the notion, we will be missing a central concept in our attempts to understand the commercial world that we inhabit." (Tallant - Donati, 2020: 3) Economic activities can be improved only if all actors/stakeholders in the process develop a clear understanding of what constitutes trust in their mutual relationships.

\section{Concluding Remarks/Suggestions}

Identifying the roots of the present crisis of trust is only the first step on a long journey to re-establish trust in our society. The current leadership has declared its resolve to tackle this complex issue, which is a good sign and a reason for hope. The stated examples of how the Vietnamese General Secretary and our Prime Minister fought corruption (as arguably the most serious cause behind the present crisis of trust) are indications that something new might be starting in the Vietnamese society. The fight, however, is far from being over. To continue on the marked path, Vietnamese people will need to stay vigilant and serious about achieving the declared aims - both on the institutional as well as personal levels.

Firstly, they need to improve the quality of management of the leaders (i.e., state officials). They must be trained and encouraged to resolutely handle all violations and incompetent behavior of public servants. Degenerate (corrupt) and incompetent cadres must be replaced with individuals who are competent and morally trustworthy. In this way, the management team will gradually attract talented people who are skilled and dedicated to work for their country.

Secondly, institutional reform is needed to create conditions for long-term development. Before launching their new policies, the Party and the Government need to learn to listen to people's ideas. This means that legitimate channels of communication must remain open for the Party and the Government to receive the much-needed critical feedback that can be implemented constructively in new policies, social norms, and (hopefully) behavioral patterns of state officials on all levels. Constructive feedback will help those in power stay relevant and connected to people's real needs and interests. In this way, policies will be adjusted and perfected.

Thirdly, respect for what is just and righteous must be promoted. This can be done institutionally on the level of laws and regulations but also personally via cultural and educational activities. People need to be encouraged to reflect on what is right and wrong, what is desirable, and what solutions are sustainable long-term (and not merely expedient for the present). The essential part of this solution is a stable, democratic environment. Lack of democracy will result in a society where there is no place for trust. This is so because without democratic principles, there cannot be the rule of law, and without the rule of law, there can be no just society. And, again, without justice and righteousness, there can be no trust and no genuine prosocial thinking and action.

People can be led by a good example of their leaders. They will give more effort to their tasks and serve their country better if they see that their country, represented by its leaders, takes their needs seriously and administers justice impartially. The citizens' willingness to sacrifice and live selflessly will be promoted in a just environment of a functioning democracy. Their political allegiance will be strengthened in an environment where there is an open conversation with the government about the successes and failures of existing policies; where there is room for honest, critical feedback; and where there is willingness to learn from past mistakes. 
Another important element that may help the Vietnamese society on it is way to building a culture of trust is an emphasis on tolerance and solidarity applied holistically on the overlapping sectors of the society. A philosophical approach that might accomplish this is called the 'philosophy of covenantal pluralism.' It is "a robust, relational, and non-relativistic paradigm of citizenship that emphasizes both legal equality and neighborly solidarity. It calls not only for a constitutional order characterized by equal rights and responsibilities but also a culture of engagement characterized by relationships of mutual respect and protection." (Stewart - Seiple Hoover, 2020: 1)

Besides paying attention to social solidarity across the existing social strata of citizens, a broader environmental solidarity is needed. Changed lifestyles that will reflect this need, along with the intentional cultivation of harmony across generations, professions, and/or geographical, cultural, and religious specifics among the Vietnamese population will be conducive to increased prosperity and stability (Nguyen, 2008). A fitting historical example promoting such principles is embodied in the figure of Nguyen Binh Khiem (1491-1585), a prominent 16th century philosopher and poet. Among other things, his emphasis on the interconnectedness of all reality and the existence of an intrinsic natural order that can be perceived and reflected upon are priceless contributions to our current socio-ethical discourse (Le Le, 1957; Cheung et al., 2003).

\section{Bibliographic references}

ANDOW, J. 2020. Why don't we trust moral testimony?. In: Mind \& Language, vol. 35, n. 4, pp. 456-474.

CHEUNG, T. - CHAN, H. - CHAN, K. - KING, A. - CHIU, C. - YANG, C. 2003. On Zhongyong Rationality: The Confucian Doctrine of the Mean as a Missing Link between Instrumental Rationality and Communicative Rationality. In: Asian Journal of Social Science, vol. 31, n. 1, pp. 107-127.

CHRISTENSEN, A.M.S. - ERIKSEN, C. 2021. Each Other's World, Each Other's Fate-Logstrup's Conception of Basic Trust. In: International Journal of Philosophical Studies, vol. 29, n. 1, pp. 24-43.

COVEY, S.R. - MERRILL, R.R. 2006. The speed of trust: The one thing that changes everything. London: Simon and Schuster.

DANG, D.A. - DANG, K.K. - DANG, V.A. - VU, T.L. 2020. The effects of trust and land administration on economic outcomes: Evidence from Vietnam. In: Food Policy, vol. 94, n. 1, p. 101813.

DANG, N.V. 1993. The flood myth and the origin of ethnic groups in Southeast Asia. In: Journal of American Folklore, vol. 106, n. 421, pp. 304-337.

DAWEI, Z. (ed.). 2015. Future Information Engineering and Manufacturing Science: Proceedings of the 2014 International Conference on Future Information Engineering and Manufacturing Science (FIEMS 2014), June 26-27, 2014, Beijing, China. Vol. 2. Beijing: CRC Press.

DO, T.K.H. - VALCO, M. 2018. The philosophy of human rights and the 'political man': Engaging the intellectual legacy of Ho Chi Minh in a technological era. In: XLinguae, vol. 11, n. 2, pp. 608-624.

FFORDE, A. - HOMUTOVA, L. 2017. Political authority in Vietnam: is the Vietnamese communist party a paper Leviathan? In: Journal of Current Southeast Asian Affairs, vol. 36, n. 3, pp. 91-118.

FISHER, A. - TALLANT, J. 2020. Trust in education. In: Educational Philosophy and Theory, vol. 52, n. 7, pp. 780-790.

FLORES, F. - SOLOMON, R.C. 1998. Creating trust. In: Business Ethics Quarterly, vol. 8, n. 2, pp. 205-232.

FROMM, E. 1961. Das Menschenbild bei Marx. Tubingen: Rainer Funk Verlag.

XLinguae, Volume 14 Issue 3, June 2021, ISSN 1337-8384, eISSN 2453-711X 
FUKUYAMA, F. 1996. Trust: human nature and the reconstitution of social order. London: Simon and Schuster.

FUKUYAMA, F. 2001. Social capital, civil society and development. In: Third world quarterly, vol. 22, n. 1, pp. 7-20.

GIDDENS, A. 1996. Social Theory and Modern Sociology. Stanford: Stanford University Press.

HAIDT, J. 2006. The happiness hypothesis: Putting ancient wisdom and philosophy to the test of modern science. London: Random House.

HOLLIS, M. 1998. Trust within reason. Cambridge: Cambridge University Press.

LE, T.K. - LE, A.T. 1957. Nguyen Binh Khiem - Philosophical poet. Hanoi: Culture Publishing House.

MARKOVA, I. - LINELL, P. - GILLESPIE, A. 2007. Trust and distrust in society. In I. Markova \& A. Gillespie (eds.). Trust and distrust: Socio cultural perspectives. Charlotte, NC: Information Age Publishing, Inc., pp. 3-27. Available online: https://www.academia.edu/1308584/Trust_and_distrust_in_society

MARTY, M.E. 2010. Building Cultures of Trust. Grand Rapids: William B. Eerdmans Publishing Company, USA.

NGUYEN, T.D. 2008. The role of religious tolerance and social solidarity in creating peace and maintaining social stability. In: Journal of Philosophy, vol. 5, n. 5, pp. 3745.

NGUYEN, T.A. - KNIGHT, R. - MANT, A. - RAZEE, H. - BROOKS, G. - DANG, T.H. - ROUGHEAD, E.E. 2018. Corruption practices in drug prescribing in Vietnam-an analysis based on qualitative interviews. In: BMC health services research, vol. 18, n. 1, pp. 1-20.

PEPERZAK, A.T. 2013. Trust: who or what might support us?. New York: Fordham University Press.

ROLIN, K.H. 2020. Objectivity, trust and social responsibility. In: Synthese, pp. 1-21, doi.org/10.1007/s11229-020-02669-1

SCHWEIDLER, W. 2020. On the Ontological Status of Trust: Robert Spaemann's Philosophy of the Person as a Promise. In: Fabris A. (ed.) Trust. Trust 2020. Studies in Applied Philosophy, Epistemology and Rational Ethics, vol 54. Springer, Cham. doi.org/10.1007/978-3-030-44018-3_8.

STEWART, W.C. - SEIPLE, C. - HOOVER, D.R. 2020. Toward a Global Covenant of Peaceable Neighborhood: Introducing the Philosophy of Covenantal Pluralism. In: The Review of Faith \& International Affairs, vol. 18, n. 4, pp. 1-17.

TALLANT, J. - DONATI, D. 2020. Trust: from the Philosophical to the Commercial. In: Philosophy of Management, vol. 19, n. 1, pp. 3-19.

USLANER, E.M. 2002. The moral foundations of trust. Cambridge: Cambridge University Press.

VANZANT, I. 2015. Trust: Mastering the 4 Essential Trusts: Trust in God, Trust in Yourself, Trust in Others, Trust in Life. New York: Smiley Books.

VNA. 2020. Former transport minister prosecuted for State asset management violations. In: VOV [online]. Published on Tuesday, 09:32, 27/10/2020. Available online: https://vov.vn/en/society/former-transport-minister-prosecuted-for-state-assetmanagement-violations-813020.vov

VOV. 2021. PM: Administrative reforms contribute to national achievements. In: Voice of Vietnam [online]. Published on Thursday, March 18, 2021. Available online: https://vovworld.vn/en-US/news/pm-administrative-reforms-contribute-to-nationalachievements-963862.vov

YANG, J. - DONG, C. - CHEN, Y. 2021. Government's Economic Performance Fosters Trust in Government in China: Assessing the Moderating Effect of Respect for Authority. In: Social Indicators Research, vol. 154, n. 2, pp. 545-558.

YEO, A.I. - GREEN, M.N. 2015. Living in an Age of Mistrust: An Interdisciplinary Study of Declining Trust and How to Get It Back. London: Routledge. 
CPV, 2012: The Fourth Conference of the 11th Party Central Committee issued Resolution No.12-NQ/TW "Current urgent issues on Party building on 16 January 2012: Available online: https://tulieuvankien.dangcongsan.vn/van-kien-tu-lieu-vedang/hoi-nghi-bch-trung-uong/khoa-xi/nghi-quyet-so-12-nqtw-ngay-16012012-hoinghi-lan-thu-4-ban-chap-hanh-trung-uong-dang-khoa-xi-ve-mot-so-van-de-cap-553

Words: 7243

Characters: 47523 (26,40 standard pages)

Assoc. Prof. Dr. Thu Nghia Nguyen

Vietnam Academy of Social Sciences

Institute of Philosophy

59 Langha, Badinh, Hanoi,

Vietnam

nguyenthunghia75@gmail.com 